\title{
Frequency, Determinants, and Costs of Recommendations for Additional Imaging in Clinical ${ }^{18}$ F-FDG PET/CT Reports
}

\author{
Hasan M. Alesawi, Derya Yakar, Andor W.J.M. Glaudemans, and Thomas C. Kwee \\ Medical Imaging Centre, Department of Radiology, Nuclear Medicine, and Molecular Imaging, University Medical Centre \\ Groningen, University of Groningen, Groningen, The Netherlands
}

\begin{abstract}
Our purpose was to determine the frequency, determinants, and costs of recommendations for additional imaging (RAls) in clinical ${ }^{18} \mathrm{~F}-$ FDG PET/CT reports. Methods: This retrospective study included a random sample of $2,643{ }^{18} \mathrm{~F}-\mathrm{FDG}$ PET/CT scans that were performed for various clinical reasons at a tertiary-care academic medical center without financial incentives for self-referral, within a 1.5-y period. Results: Ninety-eight (3.7\%) of 2,643 ${ }^{18} \mathrm{~F}-\mathrm{FDG}$ PET/CT reports contained an RAl. None of the investigated variables (patient age, hospital status [inpatient or outpatient], indication for ${ }^{18} \mathrm{~F}$ FDG PET/CT scanning [oncologic, infection/inflammation, or miscellaneous], type of ${ }^{18} \mathrm{~F}-\mathrm{FDG}$ PET/CT scan [low-dose ${ }^{18} \mathrm{~F}-\mathrm{FDG}$ $\mathrm{PET} / \mathrm{CT}$ or low-dose ${ }^{18} \mathrm{~F}-\mathrm{FDG} \mathrm{PET} / \mathrm{CT}$ combined with diagnostic CT of any body region], or years of experience of the [most senior] signing author) was univariately associated with the presence of an $\mathrm{RAI}$ in the ${ }^{18} \mathrm{~F}-\mathrm{FDG} \mathrm{PET} / \mathrm{CT}$ report. The hypothesis that RAls more frequently occur when the anatomic area to which the RAI relates is not covered by a diagnostic CT scan (as part of the ${ }^{18} \mathrm{~F}-\mathrm{FDG}$ PET/CT examination) was also rejected ( $P=0.419)$. The total costs of all RAls (regardless of whether they were actually performed by the referring clinicians) were $€ 23,922.21$ ( $\$ 27,065.47)$, which corresponds to an average of $€ 9.08$ ( $\$ 10.27)$ RAl costs per ${ }^{18} \mathrm{~F}-\mathrm{FDG}$ PET/CT exam. The total costs of all RAls that were actually performed by the referring clinicians were $€ 16,498.62$ ( $\$ 18,666.46)$, which corresponds to an average of $€ 6.26$ (\$7.08) RAl costs per ${ }^{18} \mathrm{~F}-\mathrm{FDG}$ PET/CT exam. Conclusion: RAls in ${ }^{18} \mathrm{~F}$-FDG PET/CT reports in a European tertiary-care academic medical center without financial incentives for self-referral are infrequent, cannot be anticipated, and result in relatively low overall costs.
\end{abstract}

Key Words: costs; ${ }^{18} \mathrm{~F}-\mathrm{FDG}$ PET/CT; recommendation for additional imaging; report

J Nucl Med 2019; 60:1228-1233

DOI: 10.2967/jnumed.118.223362

\section{$\mathbf{P}$}

ET with the radiotracer ${ }^{18} \mathrm{~F}-\mathrm{FDG}$ is the most widely used molecular imaging technique in clinical practice, most notably in oncology (1). Its use has rapidly increased in the past decade, mainly thanks to the emergence of hybrid scanners combining PET with CT (1). Because ${ }^{18} \mathrm{~F}-\mathrm{FDG}$ PET/CT is considered an advanced and costly imaging method (2), it would ideally provide sufficient diagnostic confidence to minimize the need for further

Received Nov. 12, 2018; revision accepted Feb. 2, 2019.

For correspondence contact: Derya Yakar, University Medical Centre Groningen, Hanzeplein 1, P.O. Box 30.001, 9700 RB Groningen, The Netherlands.

E-mail: d.yakar@umcg.nl

Published online Feb. 22, 2019.

COPYRIGHT (C 2019 by the Society of Nuclear Medicine and Molecular Imaging. imaging examinations. However, in clinical practice it is not uncommon for reporting imaging physicians to recommend additional imaging examinations to reduce uncertainty about equivocal or even negative findings on ${ }^{18} \mathrm{~F}-\mathrm{FDG}$ PET/CT. These recommendations for additional imaging (RAIs) may have a negative impact on healthcare use and costs $(3,4)$.

In a study by Sistrom et al. (5), 10,421 of 43,917 PET-only examinations $(23.7 \%)$ had at least 1 RAI in the dictated report. However, their results do not apply to hybrid PET/CT, which is at present the standard of care. Another study, by Shinagare et al. (6), investigated 250 oncologic ${ }^{18} \mathrm{~F}$-FDG PET/CT reports, which contained 84 RAIs (33.6\%). However, they did not include indications other than oncologic diseases for performing ${ }^{18} \mathrm{~F}-\mathrm{FDG} \mathrm{PET} / \mathrm{CT}$ (6). Furthermore, both Sistrom et al. and Shinagare et al. investigated only a limited number of factors associated with RAIs, and neither one of them determined the costs of these RAIs. Moreover, both studies were performed in the United States, where imaging physicians may tend to give more RAIs because of the higher risk of malpractice suits than in other countries $(7,8)$. Studies performed outside the United States on this topic are currently lacking. More research on the issue of RAIs in clinical ${ }^{18} \mathrm{~F}-\mathrm{FDG}$ PET/ CT is needed to assess the extent of this problem and to identify potential solutions to reduce this type of imaging overutilization.

The purpose of this study was therefore to determine the frequency, determinants, and costs of RAIs in clinical ${ }^{18} \mathrm{~F}-\mathrm{FDG}$ PET/ CT reports.

\section{MATERIALS AND METHODS}

\section{Study Design and Patients}

The local institutional review board waived the requirement for informed consent for this retrospective study (waiver 2017/433). Between January 2016 and June 2017, a consecutive number of 5,564 (whole-body) ${ }^{18}$ F-FDG PET/CT scans were performed at the University Medical Center Groningen. The University Medical Center Groningen is a tertiary-care academic medical center in The Netherlands where all physicians are paid straight salaries, regardless of the number of procedures performed. Therefore, it provides an ideal environment to study the frequency of RAIs that are not affected by financial incentives for self-referral (9). In total, 3,000 of these 5,564 ${ }^{18} \mathrm{~F}-\mathrm{FDG}$ PET/CT examinations were selected using the random-sampling function in Excel (Microsoft). Of these 3,000 ${ }^{18} \mathrm{~F}$-FDG PET/CT examinations, 357 were excluded because they contained no clinical ${ }^{18} \mathrm{~F}-\mathrm{FDG}$ PET/CT report since they were either part of a research study or performed for interpretation at another hospital. Thus, 2,643 ${ }^{18} \mathrm{~F}-\mathrm{FDG}$ PET/CT examinations with a clinical report remained and were finally included.

\section{${ }^{18}$ F-FDG PET/CT Acquisition and Interpretation}

All 2,643 ${ }^{18} \mathrm{~F}$-FDG PET/CT examinations were acquired using an EANM/EARL (European Association of Nuclear Medicine/ResEARch 
4 Life)-accredited hybrid PET/CT system (Biograph mCT PET/CT; Siemens). Patients fasted for at least $6 \mathrm{~h}$ before $3 \mathrm{MBq}$ of ${ }^{18} \mathrm{~F}-\mathrm{FDG}$ per kilogram of body weight were intravenously injected. Blood glucose levels were checked to be less than $11 \mathrm{mmol} / \mathrm{L}$ before ${ }^{18} \mathrm{~F}$-FDG administration. After staying supine and solitary in a quiet environment at $20^{\circ} \mathrm{C}-22^{\circ} \mathrm{C}$ for approximately $60 \mathrm{~min}$, patients underwent low-dose $\mathrm{CT}$ scanning (with a tube voltage of $100 \mathrm{kVp}$ and an effective tube current-time product of $30 \mathrm{mAs}$ ) from cranial vertex to mid thighs or feet, followed by PET scanning (with $3 \mathrm{~min}$ per bed position) in the caudocranial direction. Full-dose intravenous contrast-enhanced CT (with tube voltage and tube setting adjusted according to age, weight, and body region) was also performed in some patients, depending on the request of the referring clinician. Low-dose ${ }^{18}$ F-FDG PET/CT examinations were evaluated as part of standard clinical care by different nuclear medicine physicians using a dedicated workstation (Syngo.via; Siemens) and reported using a speech recognition system. If a concomitant diagnostic (full-dose, intravenous contrast-enhanced) CT scan was performed, it was evaluated by a radiologist using a dedicated workstation (Vue PACS, version 11.4.1.1102; Carestream Health, Inc.). Findings from low-dose ${ }^{18} \mathrm{~F}-\mathrm{FDG}$ PET/CT and diagnostic CT data sets were dictated in a single report with an integrated conclusion by combining the nuclear medicine physician's and radiologist's reports. All reports were dictated in a free-text form, with an ending paragraph that contained a conclusion and possible RAIs.

\section{Data Extraction}

A research fellow evaluated all 2,643 ${ }^{18}$ F-FDG PET/CT reports and corresponding patient data that were stored in the hospital's electronic database. The following variables were extracted from each ${ }^{18} \mathrm{~F}-\mathrm{FDG}$ PET/CT report: patient age, sex, hospital status at time of ${ }^{18} \mathrm{~F}-\mathrm{FDG}$ PET/ CT scanning (inpatient or outpatient), indication for ${ }^{18} \mathrm{~F}-\mathrm{FDG}$ PET/CT scanning (oncologic [including cancer subtype], infection/inflammation, or miscellaneous), type of ${ }^{18} \mathrm{~F}$-FDG PET/CT scan (low-dose ${ }^{18} \mathrm{~F}-\mathrm{FDG}$ PET/CT or low-dose ${ }^{18} \mathrm{~F}-\mathrm{FDG}$ PET/CT combined with diagnostic CT of any body region), years of experience of the author (or most senior author in the case of multiple readers) who signed the report (calculated in years from date of completion of residency), and presence or absence of an RAI in the dictated report. An RAI was defined as advice to perform a specific additional diagnostic imaging examination. Recommendations for clinical correlation, consultations with other medical specialties, and other nonimaging diagnostic tests or (therapeutic) interventions were excluded. Recommendations to reevaluate specific findings at the next scheduled ${ }^{18} \mathrm{~F}-\mathrm{FDG} \mathrm{PET} / \mathrm{CT}$ examinations were also excluded.

\section{Statistical Analysis}

Basic ${ }^{18} \mathrm{~F}-\mathrm{FDG}$ PET/CT and patient data were descriptively analyzed. The frequency of RAIs in the 2,643 ${ }^{18} \mathrm{~F}$-FDG PET/CT reports was calculated. Univariate logistic regression analyses were performed to determine the association of patient age, different age groups ( $<18 \mathrm{y}$, $>65 \mathrm{y}$, and $>80 \mathrm{y}$ ), sex, hospital status, indication for ${ }^{18} \mathrm{~F}-\mathrm{FDG}$ PET/ CT scanning, type of ${ }^{18} \mathrm{~F}-\mathrm{FDG}$ PET/CT scan, and years of experience of the (most senior) signing author with the presence of an RAI in the ${ }^{18} \mathrm{~F}$ FDG PET/CT report. Furthermore, the hypothesis was tested that RAIs more frequently occur when the anatomic area to which the RAI relates is not covered by a diagnostic CT scan (as part of the ${ }^{18} \mathrm{~F}-\mathrm{FDG}$ PET/CT examination). This was done using a general $Z$ test, with the reference percentage set at $50 \%$. Finally, the costs of all RAIs and RAIs that were actually followed by the referring clinician were calculated as totals and per single ${ }^{18} \mathrm{~F}$-FDG PET/CT examination (i.e., total costs divided by the 2,643 ${ }^{18}$ F-FDG PET/CT examinations), according to Dutch Healthcare Authority (Nederlandse Zorgautoriteit, NZa) tariffs. $P$ values of less than 0.05 were considered statistically significant. All statistical analyses were performed using IBM Statistical Package for the Social Sciences, version 23 (SPSS).

\section{RESULTS}

\section{${ }^{18}$ F-FDG PET/CT Scans and Patients}

The 2,643 ${ }^{18}$ F-FDG PET/CT scans were performed in 1,873 unique patients, of whom 1,056 were male and 817 female, with a mean age $( \pm \mathrm{SD})$ of $60.4 \pm 16.2$ y (range, 0-95 y). In 493 patients $(26.3 \%)$, more than $1{ }^{18} \mathrm{~F}-\mathrm{FDG}$ PET/CT scan was performed; $411(15.6 \%){ }^{18} \mathrm{~F}-\mathrm{FDG}$ PET/CT scans were acquired while patients were hospitalized, and 2,232 (84.4\%) were acquired in the outpatient setting. ${ }^{18} \mathrm{~F}$-FDG PET/CT scans were performed in oncologic settings in $2,171(82.1 \%)$, for evaluation of infectious/ inflammatory disease in $263(10.0 \%)$, and for miscellaneous reasons in 209 (7.9\%). Oncologic ${ }^{18}$ F-FDG PET/CT scans were made for breast cancer $(n=96)$, gastrointestinal cancer $(n=327)$, head-neck cancer $(n=252)$, lung cancer $(n=616)$, lymphoma $(n=403)$, melanoma $(n=143)$, myeloma $(n=46)$, and other cancer types or indications $(n=288)$. In $1,448(54.8 \%)$, additional diagnostic CT was performed (chest-only in 482 scans; chest and abdomen in 375 scans; neck, chest, and abdomen in 352 scans; neck and chest in 79 scans; neck-only in 62 scans; abdomen-only in 56 scans; heart in 33 scans; heart and abdomen in 2 scans; lower legs in 2 scans; brain in 1 scan; neck and abdomen in 1 scan; upper arms in 1 scan; upper legs in 1 scan; and knee in 1 scan). Thirtyone different nuclear medicine physicians and radiologists evaluated the $2,643{ }^{18} \mathrm{~F}-\mathrm{FDG}$ PET/CT scans. Years of experience of the signing author (or most senior author in case of multiple readers) was $11.7 \pm 5.7 \mathrm{y}$ (range, $0-30 \mathrm{y}$ ).

\section{RAls: Frequency and Determinants}

An RAI was found in 98 of 2,643 ${ }^{18} \mathrm{~F}$-FDG PET/CT reports, corresponding to an RAI frequency of $3.7 \%$ (95\% confidence interval, $3.1 \%-4.5 \%$ ). Five of these RAI-containing ${ }^{18} \mathrm{~F}-\mathrm{FDG}$ PET/ CT reports had 2 RAIs. RAI type (imaging modality and body region) and location of perceived abnormality on ${ }^{18} \mathrm{~F}-\mathrm{FDG}$ PET/ CT for which an RAI was given are shown in Table 1. In 1 patient, 6 of the same RAIs (ultrasonography of the thyroid gland with fine-needle aspiration) were given in the reports of 6 consecutive follow-up ${ }^{18} \mathrm{~F}$-FDG PET/CT scans. There were no other ${ }^{18} \mathrm{~F}-\mathrm{FDG}$ $\mathrm{PET} / \mathrm{CT}$ reports in this study that contained the same RAI in the same patient. Since this particular case represents clinical practice and the corresponding double-counted RAIs constituted only 5\% of all RAIs, it was not corrected for in the statistical analysis. At univariate analysis, none of the investigated variables (patient age and different age groups, sex, hospital status, indication for ${ }^{18} \mathrm{~F}$ FDG PET/CT scanning, type of ${ }^{18}$ F-FDG PET/CT scan, and years of experience of the [most senior] signing author) was associated with the presence of an RAI in the ${ }^{18} \mathrm{~F}$-FDG PET/CT report (Table 2). Furthermore, the hypothesis that RAIs more frequently occur when the anatomic area to which the RAI relates is not covered by a diagnostic CT scan (as part of the ${ }^{18} \mathrm{~F}-\mathrm{FDG}$ PET/CT examination) was also rejected $(P=0.419)$. Representative cases are shown in Figures 1 and 2.

\section{RAls: Types and Costs}

Of the 98 RAIs, 40 (40.8\%) involved ultrasonography, 20 (20.4\%) CT, 15 (15.3\%) MRI, 3 (3.1\%) previously unscheduled ${ }^{18} \mathrm{~F}-\mathrm{FDG}$ PET/CT, 2 (2.0\%) leukocyte scintigraphy, $1(1.0 \%){ }^{68} \mathrm{Ga}-$ DOTATOC PET/CT, 1 (1.0\%) renography, and 1 (1.0\%) mammography. Four $(4.1 \%)$ were combined RAIs $\left(1{ }^{18} \mathrm{~F}-\mathrm{FDG}\right.$ PET/CT and diagnostic CT of the neck, 1 mammography and ultrasonography, 1 mammography and MRI, and $1 \mathrm{MRI}$ and ultrasonography), 2 were RAIs for either CT or MRI (2.0\%), and 9 (9.2\%) RAIs were not 
TABLE 1

Data for Location of Perceived Abnormality on ${ }^{18}$ F-FDG PET/CT for Which RAI Was Given

\begin{tabular}{|c|c|c|c|}
\hline Imaging modality & Body region & Location on ${ }^{18} \mathrm{~F}-\mathrm{FDG}$ PET/CT & $n$ \\
\hline \multirow[t]{11}{*}{ Ultrasonography } & Neck & Thyroid gland & 30 \\
\hline & & Neck $^{*}$ & 1 \\
\hline & & Parotid gland & 1 \\
\hline & Abdomen & Liver & 3 \\
\hline & & Urinary bladder & 2 \\
\hline & & Cecum & 1 \\
\hline & & Kidneys & 1 \\
\hline & & Pancreas & 1 \\
\hline & Chest & Breasts & 1 \\
\hline & & Heart & 1 \\
\hline & Pelvis & Femoral lymph nodes & 1 \\
\hline \multirow[t]{13}{*}{ CT } & Abdomen & Liver & 5 \\
\hline & & Abdomen* & 2 \\
\hline & & Adrenal glands & 1 \\
\hline & & Ascending colon & 1 \\
\hline & & Cecum & 1 \\
\hline & & Kidneys & 1 \\
\hline & & Kidneys and ovaries & 1 \\
\hline & & Pancreas & 1 \\
\hline & & Urinary bladder & 1 \\
\hline & Chest & Lungs & 9 \\
\hline & Chest and abdomen & Lungs and kidneys & 1 \\
\hline & Neck & Right side of neck* & 1 \\
\hline & Neck and chest & Neck and chest* & 1 \\
\hline \multirow[t]{10}{*}{ MRI } & Abdomen & Liver & 8 \\
\hline & & Pancreas & 2 \\
\hline & & Adrenal glands & 1 \\
\hline & & Lumbar spine & 1 \\
\hline & Neck & Cervical spine & 1 \\
\hline & & Cricoid & 1 \\
\hline & & Hypopharynx & 1 \\
\hline & & Mandible & 1 \\
\hline & Chest & Chest wall & 1 \\
\hline & Head & Brain & 1 \\
\hline \multirow[t]{3}{*}{${ }^{18} \mathrm{~F}-\mathrm{FDG} \mathrm{PET} / \mathrm{CT}$} & Abdomen & Liver & 1 \\
\hline & Chest & Lungs, mediastinal and hilar lymph nodes & 1 \\
\hline & Neck and chest & Cervical, mediastinal and hilar lymph nodes & 1 \\
\hline \multirow[t]{2}{*}{ Leukocyte scintigraphy } & Pelvis & Hips & 1 \\
\hline & Upper body & Humerus & 1 \\
\hline${ }^{68} \mathrm{Ga}-\mathrm{DOTATOC} \mathrm{PET/CT}$ & Chest & Heart & 1 \\
\hline $\mathrm{CT}$ and ${ }^{18} \mathrm{~F}-\mathrm{FDG} \mathrm{PET} / \mathrm{CT}$ & Neck & Oropharynx & 1 \\
\hline Mammography & Chest & Breasts & 1 \\
\hline Mammography and MRI & Chest and abdomen & Breasts and uterine cervix & 1 \\
\hline Renography & Abdomen & Kidneys & 1 \\
\hline Ultrasonography and MRI & Neck and abdomen & Thyroid gland and liver & 1 \\
\hline
\end{tabular}

1230 The Journal of Nuclear Medicine • Vol. 60 • No. 9 • September 2019 
TABLE 2

Univariate Logistic Regression Analysis on Association of Several Variables with RAI in ${ }^{18}$ F-FDG PET/CT Report

\begin{tabular}{|c|c|c|c|}
\hline Variable & Odds ratio & $95 \% \mathrm{Cl}$ & $P$ \\
\hline \multicolumn{4}{|l|}{ Patient age } \\
\hline Years (continuous scale) (range, 0-117 y) & 1.002 & $0.989-1.015$ & 0.759 \\
\hline Patients $<18$ y $(n=131)$ vs. other ages $(n=2,512)$ & 0.275 & $0.038-1.993$ & 0.201 \\
\hline Patients $\geq 18$ y and $<65$ y $(n=1,296)$ vs. other ages $(n=1,347)$ & 1.029 & $0.688-1.541$ & 0.888 \\
\hline Patients $\geq 65$ y $(n=1,216)$ vs. other ages $(n=1,427)$ & 1.084 & $0.721-1.629$ & 0.700 \\
\hline Patients $>80$ y $(n=144)$ vs. other ages $(n=2,499)$ & 0.983 & $0.393-2.458$ & 0.970 \\
\hline Sex: male $(n=1,470)$ vs. female $(n=1,173)$ & 1.376 & $0.919-2,061$ & 0.121 \\
\hline Hospital status: inpatient $(n=411)$ vs. outpatient $(n=2,232)$ & 0.902 & $0.507-1.604$ & 0.725 \\
\hline \multicolumn{4}{|l|}{ Indication for ${ }^{18} \mathrm{~F}-\mathrm{FDG}$ PET/CT scanning } \\
\hline Oncologic $(n=2,171)$ vs. other $(n=472)$ & 0.900 & $0.540-1.501$ & 0.687 \\
\hline Infection or inflammation $(n=263)$ vs. other $(n=2,380)$ & 1.150 & $0.606-2.183$ & 0.668 \\
\hline Miscellaneous $(n=209)$ vs. other $(n=2,434)$ & 1.037 & $0.496-2.167$ & 0.924 \\
\hline \multicolumn{4}{|l|}{ Cancer type (only for oncologic scans) } \\
\hline Breast $(n=96)$ vs. other cancers $(n=2,075)$ & 0.847 & $0.262-2.736$ & 0.776 \\
\hline Gastrointestinal $(n=327)$ vs. other cancers $(n=1,844)$ & 1.335 & $0.751-2.372$ & 0.338 \\
\hline Head-neck $(n=252)$ vs. other cancers $(n=1,919)$ & 0.977 & $0.482-1.980$ & 0.948 \\
\hline Lung $(n=616)$ vs. other cancers $(n=1,555)$ & 0.687 & $0.398-1.185$ & 0.163 \\
\hline Lymphoma $(n=403)$ vs. other cancers $(n=1,768)$ & 1.028 & $0.579-1.822$ & 0.926 \\
\hline Melanoma $(n=143)$ vs. other cancers $(n=2,028)$ & 1.876 & $0.917-3.838$ & 0.109 \\
\hline Myeloma $(n=46)$ vs. other cancers $(n=2,125)$ & 0.582 & $0.079-4.279$ & 0.562 \\
\hline $\begin{array}{l}\text { Type of }{ }^{18} \text { F-FDG PET/CT scan: low-dose }{ }^{18} \text { F-FDG PET/CT }(n=1,193) \text { vs. } \\
\text { low-dose }{ }^{18} \text { F-FDG PET/CT with diagnostic CT of any body region }(n=1,450)\end{array}$ & 1.259 & $0.834-1.901$ & 0.273 \\
\hline Experience of (most senior) signing author: years (continuous scale) (range, 0-30 y) & 1.007 & $0.971-1.043$ & 0.717 \\
\hline enc & & & \\
\hline
\end{tabular}

specified. To calculate RAI costs, the ${ }^{18}$ F-FDG PET/CT reports that contained these 9 unspecified RAIs were reevaluated by a radiologist to determine the most appropriate specific RAI that should have been given. These RAIs involved CT $(n=4)$, MRI $(n=3)$, and ultrasonography $(n=2)$. The total costs of all RAIs (regardless of whether they were actually performed by the referring clinicians) were estimated to be $€ 23,922.21$ ( $\$ 27,065.47)$ for $2,634{ }^{18} \mathrm{~F}-\mathrm{FDG}$ PET/CT examinations, which corresponds to an average of $€ 9.08$ (\$10.27) RAI costs per ${ }^{18} \mathrm{~F}-\mathrm{FDG}$ PET/CT examination (Supplemental Table 1; supplemental materials are available at http://jnm.snmjournals.org). Of 98 RAIs, 66 were performed by the referring clinicians, of which 55 were exactly as written in the ${ }^{18}$ F-FDG PET/CT report. The results of these 66 RAI studies are shown in Table 3. In summary, these 66 RAIs (of which 1 RAI was performed for 2 perceived lesions in different locations on ${ }^{18} \mathrm{~F}-\mathrm{FDG}$ PET/CT) yielded 32 benign findings, 19 malignant findings, 9 lesions that remained of unclear nature, and 7 cases in which no lesion was detected. The total costs of all RAIs that were actually performed by the referring clinicians were $€ 16,498.62$ (\$18,666.46), which corresponds to an average of $€ 6.26$ (\$7.08) RAI costs per ${ }^{18}$ F-FDG PET/CT examination (Supplemental Table 2).

\section{DISCUSSION}

Health-care costs pose a considerable and increasing burden on society. For example, in the United States, the health share of the gross domestic product is projected to increase from $17.6 \%$ in
2009 to $19.8 \%$ by 2020 (10). The use of advanced imaging methods such as CT, MRI, and PET is partially responsible for these health-care costs $(2,3)$. Therefore, inappropriate use of imaging has become a target for cost containment (11). One important target in this context is the issue of RAIs in radiology reports and associated costs. Interestingly, the results of this study show that RAIs in ${ }^{18} \mathrm{~F}-\mathrm{FDG}$ PET/CT reports place a rather negligible burden on the health-care system; both the frequency of RAIs and the average direct RAI costs per ${ }^{18}$ F-FDG PET/CT examination were relatively low. Importantly, to our knowledge, this study is the first of its kind that was performed in a European tertiary-care academic medical center without financial incentives for self-referral. Since RAIs are a potential source of imaging overutilization, the reported RAI frequency and costs may be used as a quality indicator for benchmarking purposes. No clinical or imaging variables (including the availability of a concomitant diagnostic CT scan) were found to be associated with the presence of an RAI in the ${ }^{18} \mathrm{~F}-\mathrm{FDG}$ PET/CT report. Therefore, there are no clear issues that can be targeted to prevent or decrease the number of RAIs when ${ }^{18} \mathrm{~F}-\mathrm{FDG}$ PET/CT examinations are performed and interpreted in a similar health-care system.

A study by Sistrom et al. (5) analyzed 5,948,342 various diagnostic imaging examinations, including angiography, CT, mammography, MRI, "nuclear medicine," PET, radiography, and ultrasonography, that were reported between 1995 and 2008. In their study, 627,064 


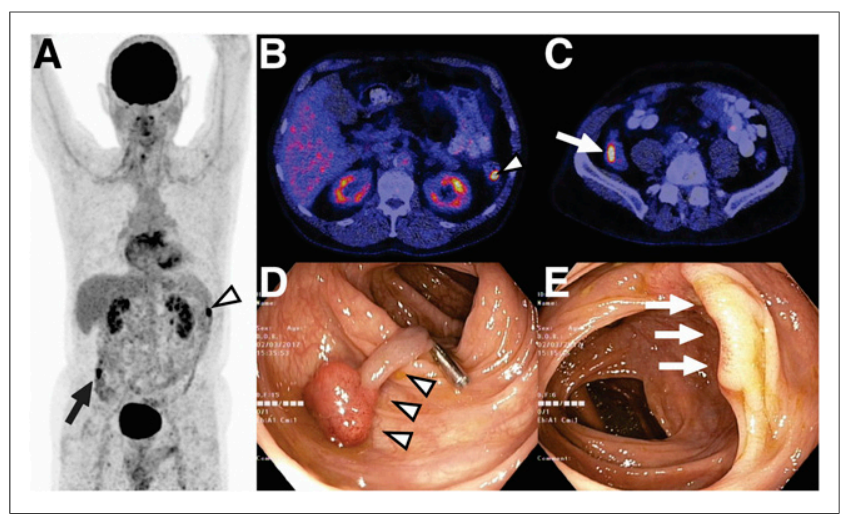

FIGURE 1. In 71-y-old man who had previously achieved complete remission after chemoradiation therapy for small cell lung carcinoma, cardiac ultrasonography (not shown) suggested pericardial effusion, and ${ }^{18} \mathrm{~F}-\mathrm{FDG}$ PET/CT was ordered to exclude malignant cause. ${ }^{18} \mathrm{~F}-\mathrm{FDG}$ PET did not show any signs of intrathoracic disease. However, 2 highly ${ }^{18} \mathrm{~F}$-FDG-avid foci were seen in large bowel (A, arrowhead and arrow), which could be localized in splenic flexure of colon and in ascending colon on fused ${ }^{18} \mathrm{~F}-\mathrm{FDG}$ PET/CT images (B, arrowhead, and C, arrow). ${ }^{18} \mathrm{~F}-\mathrm{FDG}$ PET/CT report contained advice to perform colonoscopy for further evaluation of these 2 lesions (strong recommendation). Referring physician followed this recommendation. Colonoscopy showed pedunculated polyp in splenic flexure of colon ( $D$, arrowheads) and flat tumor in ascending colon (E, arrows). Pedunculated polyp was completely removed endoscopically and proved to be tubular adenoma with lowgrade dysplasia. Flat tumor was biopsied and proved to be well to moderately differentiated adenocarcinoma, for which right-sided hemicolectomy was performed.

$(10.5 \%)$ of diagnostic imaging examinations contained at least 1 RAI in the dictated report, as detected by their natural languageprocessing algorithm. Diagnostic angiography had the fewest RAIs (3.8\%) and was set as the reference category for the odds ratios obtained from logistic regression. The modalities with the most RAIs were PET (with an odds ratio of 4.3 compared with that of angiography) followed by CT (odds ratio of 4.0 compared with that of angiography). Studies that had "positive findings" (defined as "clinically important findings" according to the natural language-processing algorithm) were more likely (odds ratio of 5.0) to have an RAI. The remaining factors that were investigated (patient location, whether a resident dictated the case, patient sex, modality, body area studied, ordering service, and radiologist's specialty division) also had significant effects on the tendency for an RAI. However, the definition of a "clinically important finding" can be regarded as subjective and was not investigated in the present study. Moreover, the other factors that were found to have a significant effect on the frequency of RAIs in the study of Sistrom et al., are probably not clinically relevant because of the very large sample sizes in that study, which is also referred to as the " $P$ value fallacy" (12). Furthermore, their automated natural language-processing method is likely less sensitive than manual abstraction. However, the most important limitations of their study are that they included a substantial number of PET-only examinations and that they did not define the radiotracer that was used in their PET examinations. Therefore, it is less meaningful to compare their results to those of the present study with respect to RAIs in ${ }^{18} \mathrm{~F}$-FDG PET/CT reports.

The only study so far that investigated RAIs in clinical ${ }^{18} \mathrm{~F}-\mathrm{FDG}$ PET/CT is the study by Shinagare et al. (6). These investigators analyzed 250 oncologic ${ }^{18} \mathrm{~F}$-FDG PET/CT reports, of which 74 contained at least $1 \mathrm{RAI}$, with a total of 84 RAIs (33.6\%). Important limitations of that study are its relatively low sample size and the fact that it included only oncologic patients. Moreover, RAI determinants and costs were not assessed. Nevertheless, the difference in RAI frequency between that study (33.6\%) and the present study $(3.7 \%)$ is striking. Differences in malpractice concerns and in the medical culture generally may be an explanation. In addition, it can be speculated that Europeans in general are more parsimonious than Americans, as is reflected in a more conservative approach to resource use in health care. Concomitant diagnostic $\mathrm{CT}$ was used in $55 \%$ of ${ }^{18} \mathrm{~F}-\mathrm{FDG}$ PET/CT examinations in the present study and in no ${ }^{18} \mathrm{~F}$-FDG PET/CT examination in the study of Shinagare et al. study. However, this does not explain the difference in RAIs between these 2 studies, given the fact that the there was no significant difference in RAI frequency between ${ }^{18} \mathrm{~F}$-FDG PET/CT scans that were made with versus without concomitant diagnostic CT $(P=0.273)$. The number of RAIs in reports of low-dose ${ }^{18}$ F-FDG PET/CT scans without concomitant diagnostic $\mathrm{CT}$ in the present study remained low, with a percentage of $3.3 \%(39 / 1,193)$.

This study had several limitations. First, it was performed in a tertiary academic medical center without any financial incentives for self-referral among interpreting imaging physicians. Frequency of RAIs may well be different in nonacademic hospitals with different patient populations and in hospitals where selfreferral may be financially beneficial. Second, the analysis of the effect of the availability of a concomitant diagnostic CT scan on the frequency of RAIs may have been prone to selection bias, because patients were not randomly assigned to undergo an additional diagnostic CT scan. Furthermore, diagnostic CT scans were not uniform with regard to anatomic regions. Third, availability or nonavailability of clinical information and previous diagnostic examinations

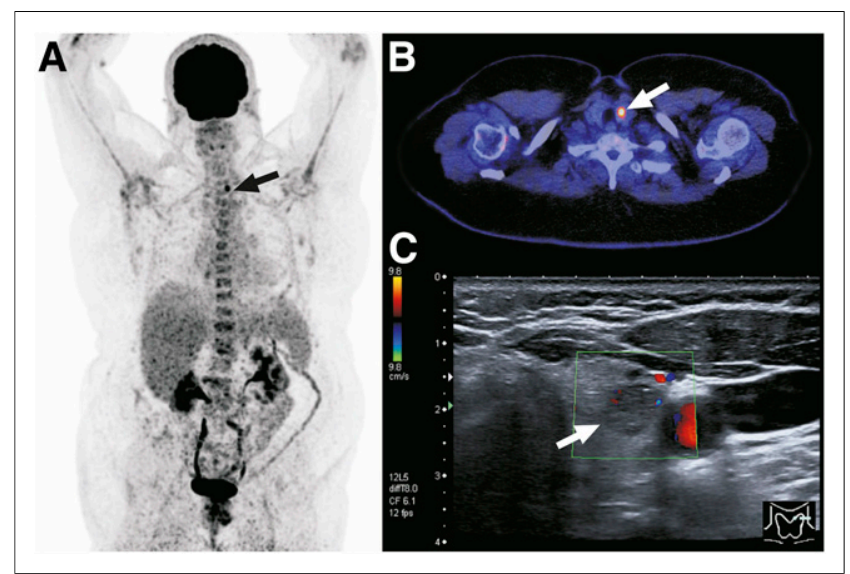

FIGURE 2. In 70-y-old woman with locally recurrent endometrial carcinoma who was already receiving preoperative radiation therapy. ${ }^{18} \mathrm{~F}$ FDG PET/CT was performed to screen for metastatic disease. ${ }^{18} \mathrm{~F}-\mathrm{FDG}$ PET showed ${ }^{18} \mathrm{~F}-\mathrm{FDG}$-avid lesion in left thyroid gland (A, arrow), which was also demonstrated on fused ${ }^{18} \mathrm{~F}-\mathrm{FDG}$ PET/CT (B, arrow), but no signs of metastatic disease elsewhere. ${ }^{18} \mathrm{~F}-\mathrm{FDG}$ PET/CT report contained advice to perform ultrasonography and fine-needle aspiration for further evaluation of this thyroid lesion (strong recommendation). Referring physician followed this recommendation. Ultrasonography showed $10-\mathrm{mm}$ nodule in left thyroid gland, and fine-needle aspiration was performed. Cytologic examination revealed benign follicular nodule (Bethesda category 2). 
TABLE 3

Results of 66 RAI Studies That Were Actually Performed by Referring Clinicians

\begin{tabular}{|c|c|c|}
\hline Description & Organ/body region & $n$ \\
\hline \multirow{11}{*}{ Benign } & Thyroid gland & 13 \\
\hline & Lungs & 7 \\
\hline & Liver & 3 \\
\hline & Kidneys & 2 \\
\hline & Cervical lymph node & 1 \\
\hline & Cricoid & 1 \\
\hline & Femoral lymph nodes & 1 \\
\hline & Heart & 1 \\
\hline & $\begin{array}{l}\text { Lungs, mediastinal } \\
\text { and hilar lymph nodes }\end{array}$ & 1 \\
\hline & Neck and chest & 1 \\
\hline & Parotid gland & 1 \\
\hline \multirow[t]{12}{*}{ Malignant } & Liver & 4 \\
\hline & Thyroid gland & 3 \\
\hline & Pancreas & 2 \\
\hline & Abdomen* & 2 \\
\hline & Adrenal gland & 1 \\
\hline & Ascending colon & 1 \\
\hline & Bladder & 1 \\
\hline & Brain & 1 \\
\hline & Hypopharynx & 1 \\
\hline & Lungs & $1^{\dagger}$ \\
\hline & Mandible & 1 \\
\hline & Uterine cervix & 1 \\
\hline \multirow[t]{6}{*}{ Indeterminate } & Liver & 2 \\
\hline & Lungs & 2 \\
\hline & Thyroid gland & 2 \\
\hline & Lumbar spine & 1 \\
\hline & Kidneys & $1^{\dagger}$ \\
\hline & Neck & 1 \\
\hline \multirow{6}{*}{$\begin{array}{l}\text { Negative (nothing } \\
\text { was found) }\end{array}$} & Liver & 2 \\
\hline & Bladder & 1 \\
\hline & $\begin{array}{l}\text { Cervical, mediastinal } \\
\text { and hilar lymph nodes }\end{array}$ & 1 \\
\hline & Hips & 1 \\
\hline & Oropharynx & 1 \\
\hline & Pancreas & 1 \\
\hline \multicolumn{3}{|c|}{$\begin{array}{l}\text { *Location cannot be further specified. } \\
{ }^{\dagger} \text { In } 1 \text { patient, perceived lung abnormalities on }{ }^{18} \mathrm{~F}-\mathrm{FDG} \text { PET/CT } \\
\text { proved to be malignant, whereas perceived kidney abnormalities } \\
\text { on }{ }^{18} \mathrm{~F}-\mathrm{FDG} \text { PET/CT remained of indeterminate nature after RAl } \\
\text { study was actually performed (CT scan of both chest and abdo- } \\
\text { men in this case was counted as } 1 \text { RAI). }\end{array}$} \\
\hline
\end{tabular}

may also have affected the frequency of RAIs, but these data were too heterogeneous to be meaningfully quantified and analyzed. Interestingly, a previous study reported that the frequency of RAIs in abdominal or pelvic CT or MRI reports could have been avoided based on information contained in prior imaging examinations in approximately $4.1 \%$ (13). Fourth, the appropriateness of the RAIs that were given was beyond the scope of this study and not investigated.

\section{CONCLUSION}

RAIs in ${ }^{18} \mathrm{~F}$-FDG PET/CT reports in a European tertiary-care academic medical center without financial incentives for self-referral are infrequent, cannot be anticipated, and result in relatively low overall costs.

\section{DISCLOSURE}

No potential conflict of interest relevant to this article was reported.

\section{KEY POINTS}

QUESTION: What are the frequency, determinants, and costs of RAls in clinical ${ }^{18}$ F-FDG PET/CT reports?

PERTINENT FINDINGS: In this retrospective study 98 (3.7\%) of 2,643 ${ }^{18} \mathrm{~F}-\mathrm{FDG}$ PET/CT reports contained an RAI and none of the investigated variables (e.g., patient, imaging or reporting physician characteristics) was associated with the presence of an RAI. The average costs of all RAls (regardless of whether they were performed by the referring clinicians ) were $€ 9.08 \mathrm{RAl}(\$ 10.27)$ per 18F-FDG PET/CT exam, whereas average costs for RAls that were actually performed by the referring clinicians were $€ 6.26$ (\$7.08) RAI per ${ }^{18} \mathrm{~F}-\mathrm{FDG}$ PET/CT exam.

IMPLICATIONS FOR PATIENT CARE: RAIS in ${ }^{18} \mathrm{~F}-\mathrm{FDG}$ PET/CT reports in a European tertiary-care academic medical center without financial incentives for self-referral are infrequent, cannot be anticipated, and result in relatively low overall costs.

\section{REFERENCES}

1. Hess S, Blomberg BA, Zhu HJ, Høilund-Carlsen PF, Alavi A. The pivotal role of FDG-PET/CT in modern medicine. Acad Radiol. 2014;21:232-249.

2. Hillman BJ, Goldsmith JC. The uncritical use of high-tech medical imaging. N Engl J Med. 2010;363:4-6.

3. Hendee WR, Becker GJ, Borgstede JP, et al. Addressing overutilization in medical imaging. Radiology. 2010;257:240-245.

4. Blaivas M, Lyon M. Frequency of radiology self-referral in abdominal computed tomographic scans and the implied cost. Am J Emerg Med. 2007;25:396-399.

5. Sistrom CL, Dreyer KJ, Dang PP, et al. Recommendations for additional imaging in radiology reports: multifactorial analysis of 5.9 million examinations. Radiology. 2009;253:453-461.

6. Shinagare AB, Shyn PB, Sadow CA, Wasser EJ, Catalano P. Incidence, appropriateness, and consequences of recommendations for additional imaging tests in oncological PET/CT reports. Clin Radiol. 2013;68:155-161.

7. Jena AB, Schoemaker L, Bhattacharya J, Seabury SA. Physician spending and subsequent risk of malpractice claims: observational study. BMJ. 2015;351:h5516.

8. Gallagher TH, Waterman AD, Garbutt JM, et al. US and Canadian physicians' attitudes and experiences regarding disclosing errors to patients. Arch Intern Med. 2006;166:1605-1611.

9. Levin DC, Rao VM. The effect of self-referral on utilization of advanced diagnostic imaging. AJR. 2011;196:848-852.

10. Keehan SP, Sisko AM, Truffer CJ, et al. National health spending projections through 2020: economic recovery and reform drive faster spending growth. Health Aff (Millwood). 2011;30:1594-1605.

11. Blackmore CC, Mecklenburg RS, Kaplan GS. Effectiveness of clinical decision support in controlling inappropriate imaging. J Am Coll Radiol. 2011;8:19-25.

12. Goodman SN. Toward evidence-based medical statistics. 1: the P value fallacy. Ann Intern Med. 1999;130:995-1004.

13. Doshi AM, Kiritsy M, Rosenkrantz AB. Strategies for avoiding recommendations for additional imaging through a comprehensive comparison with prior studies. J Am Coll Radiol. 2015;12:657-663. 